\title{
Prostaglandin E2 promotes human cholangiocarcinoma cell proliferation, migration and invasion through the upregulation of $\beta$-catenin expression via EP3-4 receptor
}

\author{
MINGZHAN DU, FENG SHI, HAI ZHANG, SHUKAI XIA, MIN ZHANG, JUAN MA, XIAOMING BAI, \\ LI ZHANG, YIPIN WANG, SHANYU CHENG, QINYI YANG and JING LENG
}

Cancer Center, Department of Pathology, Nanjing Medical University, Nanjing, Jiangsu 210029, P.R. China

Received February 6, 2015; Accepted April 28, 2015

DOI: $10.3892 / o r .2015 .4043$

\begin{abstract}
Prostaglandin E2 (PGE2) is involved in cholangiocarcinoma cell proliferation, migration and invasion through E prostanoid receptors, including EP1, EP2 and EP4. However, the functions and the mechanisms of those splice variants of EP3 receptors in promoting liver cancer cell growth and invasion remain to be elucidated. In our previous studies, four isoforms of EP3 receptors, EP3-4, EP3-5, EP3-6 and EP3-7 receptors, were detected in CCLP1 and HuCCT1 cells. However, the functions of these receptors in these cells have yet to be determined. It was reported that $\beta$-catenin is closely correlated with malignancy, including cholangiocarcinoma. The present study was designed to examine the effects of 4-7 isoforms of EP3 in promoting cholangiocarcinoma progression and the mechanisms by which PGE2 increases $\beta$-catenin protein via EP3 receptors. The results showed that PGE2 promotes cholangiocarcinoma progression via the upregulation of $\beta$-catenin protein, and the EP3-4 receptor pathway is mainly responsible for this regulation. These findings reveal that PGE2 upregulated the cholangiocarcinoma cell $\beta$-catenin protein through the EP3-4R/Src/EGFR/PI3K/AKT/GSK-3 $\beta$ pathway. The present study identified the functions of EP3 and the mechanisms by which PGE2 regulates $\beta$-catenin expression and promoted cholangiocarcinoma cell growth and invasion.
\end{abstract}

\section{Introduction}

Cholangiocarcinoma is a common primary hepatobiliary malignancy that often arises from longstanding bile duct inflammation, injury, and reparative biliary epithelial cell proliferation $(1,2)$. Prostaglandin E2 (PGE2), a key product of cyclooxygenase-2, participates in the development of

Correspondence to: Professor Jing Leng, Cancer Center, Department of Pathology, Nanjing Medical University, 300 Guangzhou Road, Nanjing, Jiangsu 210029, P.R. China

E-mail: lengjing@njmu.edu.cn

Key words: prostaglandin E2, $\beta$-catenin, EP3R isoforms, cholangiocarcinoma inflammatory reactions and in oncogenesis $(3,4)$. PGE2 was able to promote tumor cell proliferation, migration, invasion and anti-apoptosis. In previous studies, PGE2 significantly promoted proliferation and invasion by upregulating the expression of survivin (5), focal adhesion kinase (4), Snail $(6,7)$, YB-1 (8), c-Myc (9) and $\beta 1$-integrin (10) in hepatocellular carcinoma cells, and by upregulating the expression of MMP2 (11) and the FUSE-binding protein 1 (12) in cholangiocarcinoma cells. It was also reported that, PGE2 promoted cell proliferation and invasion in breast (13), colon (14), ovarian (15) cancer and several other types of tumors.

The activity of PGE2 is mediated by four E prostanoid receptors (EPR), known as EP1R, EP2R, EP3R and EP4R. These constitute the $G$ protein-coupled receptors (GPCRs). Although previous studies have examined the relationship between tumor growth, invasion and EP1R, EP2R, EP4R but few studies have focused on the role EP3R. The EP3 receptor is more complicated $(12,16)$. EP3R mRNA has several splice variants that generate multiple isoforms. Five isoforms of the human EP3 receptors: EP3-4, EP3-5, EP3-6, EP3-7 and EP3-8 have been identified. Evidence of different signal transduction pathways and the regulation of gene expression among different EP receptors has also been demonstrated in a number of studies (17). Thus, the specific target of PGE2 in regulating cancer cell proliferation via EP receptors have yet to be clarified.

It was reported that $\beta$-catenin is highly correlated with cancer progression and poor prognosis. For example, the expression level of $\beta$-catenin has been shown to correlate with progression in colorectal (18), cervical (19) and prostate cancer (20). The activation of $\beta$-catenin was also involved in various stages of hepatic carcinoma (21-24) and cholangiocarcinoma $(25,26) . \beta$-catenin leads to the activation of target genes such as c-Myc (27), Snail (28) and cyclin D1 (29). Although $\beta$-catenin has been regarded as a useful biomarker of cancer progression, the detailed mechanisms for its tumor-promoting function remain to be elucidated.

In a previous study, EP3-4R, EP3-5R, EP3-6R and EP3-7R were observed in human CCLP1 and HuCCT1 cholangiocarcinoma cells (12). Overexpression of the stable transfection of EP3-4, EP3-5, EP3-6 and EP3-7 receptors to CCLP1, HuCCT1 and HEK 293T cells showed that the EP3-4 receptor is the most significant receptor in promoting the proliferation, migration 
and invasion of the cholangiocarcinoma cells. The aim of the present study was to assess the effects of the EP3R isoforms 4-7 on promoting cholangiocarcinoma cell growth and invasion and the signaling pathway whereby PGE2 upregulates $\beta$-catenin protein. Our results revealed that PGE2 upregulated $\beta$-catenin protein via the EP3-4 receptor and involved the Src EGFR, AKT and GSK-3 $\beta$ pathway. Upregulated $\beta$-catenin eventually caused increased c-Myc and Snail expression.

\section{Materials and methods}

Antibodies and reagents. Human CCLP1 and HuCCT1 cholangiocarcinoma cell lines were obtained from the Department of Transplantation Pathology, University of Pittsburgh Medical Center (UPMC; Pittsburgh, PA, USA). HEK 293T cells were obtained from the American Type Culture Collection (ATCC; Manassas, VA, USA). Dulbecco's modifed Eagle's medium (DMEM), RPMI-1640 medium, and Lipofectamine ${ }^{\mathrm{TM}} 2000$ were purchased from Invitrogen-Life Technologies (Carlsbad, CA, USA). PGE2, EP3 receptor selective antagonist L-798106, EP3 receptor agonist sulprostone, anti-EP3 antibody were purchased from Cayman Chemical Co. (Ann Arbor, MI, USA). Src inhibitor PP2 and G418 were purchased from Sigma-Aldrich (St. Louis, MO, USA). Anti-phosphorylated EGFR (Tyr1173) and anti-GAPDH antibodies were purchased from SAB Signalway Antibody, (Nanjing, China). Anti-phosphorylated AKT (Ser473), anti-phosphorylated GSK-3 $\beta$ (Ser9), anti-phosphorylated $\beta$-catenin (Ser33/37Thr41), anti-EGFR, anti-AKT, anti-GSK-3 $\beta$, anti- $\beta$-catenin, anti-Snail, anti-c-Myc antibodies, PI3K/AKT inhibitor LY294002, and EGFR inhibitor AG1478 were purchased from Cell Signaling Technology (Danvers, MA, USA). The protein assay was purchased from Bio-Rad Laboratories (Hercules, CA, USA). Electrochemiluminescence (ECL) reagents were purchased from Amersham Biosciences (Piscataway, NJ, USA). The Transwell unit was purchased from Costar Corning (Cambridge, MA, USA), while Matrigel was purchased from BD Biosciences, (Discovery Labware, Bedford, MA, USA). The cell proliferation assay reagent CCK-8 was purchased from Dojindo Laboratories (Kumamoto, Japan). Primer sequences were determiend using the PrimeScript ${ }^{\mathrm{TM}}$ RT reagent kit (Takara, Dalian, China). FastStart Essential DNA Green Master Mix was purchased from Roche Life Science (Indianapolis, IN, USA). PcDNA3.1, pcDNA-EP3-4, pcDNA-EP3-5, pcDNA-EP3-6 and pcDNA-EP3-7 plasmids were purchased from Jinsite Science and Technology Co. (Nanjing, China).

Cell culture. The cells were maintained at $37^{\circ} \mathrm{C}$ in a humidified $5 \% \mathrm{CO}_{2}$ incubator. CCLP1 and HEK 293T cells were cultured in DMEM and HuCCT1 cells in RPMI-1640 medium containing $10 \%$ fetal bovine serum (FBS).

Overexpression of EP3 receptor. The CCLP1, HuCCT1 and HEK 293T cells were exposed to a mixture of Lipofectamine 2000 and pcDNA-EP3/pcDNA3.1 control vector for $4 \mathrm{~h}$. Following removal of the transfection mixtures, fresh medium with $10 \%$ fetal bovine serum was added. On the second day, the medium was changed, and the cells were incubated with medium containing G418 sulfate for 14 days. Subsequent cultures of selected cells were routinely grown in the presence of selective pressure. Western blotting and quantitative PCR (qPCR) analyses were performed in the selected cells permanently transfected with EP3 receptors or control plasmids. The selected cells with the successful increase in EP3 proteins and mRNA expression were used for subsequent experiments.

Cell proliferation assay. Cell proliferation was determined using the CCK- 8 kit. This kit contains the WST- 8 reagent, a tetrazolium salt that can be reduced by mitochondrial dehydrogenases in viable cells to produce an orange-colored formazan dye. Briefly, $100 \mu \mathrm{l}$ of cell suspension was plated in each well of 96-well plates. After a 24-h culture to allow reattachment, the cells were incubated with sulprostone at the indicated concentrations $(0,0.1,1,5$ and $10 \mu \mathrm{M})$ and time periods. The cell proliferation reagent, WST-8 $(10 \mu \mathrm{l})$, was subsequently added to each well. The incubation was continued from $30 \mathrm{~min}$ to $4 \mathrm{~h}$ at $37^{\circ} \mathrm{C}$ and absorbance at $450 \mathrm{~nm}$ was measured using an automatic ELISA plate reader. These experiments were repeated in six individual wells.

Cell migration assay. Cells in $100 \mu \mathrm{l}$ serum-free medium in the presence or absence of sulprostone were seeded in the upper chamber. Regular medium containing 10\% FBS was added in the lower chamber as the chemoattractant. After incubation at $37^{\circ} \mathrm{C}$ for $12 \mathrm{~h}$, the cells were fixed with ethanol and stained with $0.1 \%$ crystal violet for $30 \mathrm{~min}$. After washing the cells with PBS, the cells on the upper surface of the filter were mechanically removed with a cotton swab. The invading cells on the lower surface were solubilized with $300 \mu 110 \%$ acetic acid. The absorbance was measured at $570 \mathrm{~nm}$. These experiments were repeated three times, and three wells were used for each treatment.

Cell invasion assay. The Matrigel was diluted with serumfree medium at the indicated concentrations and then $40 \mu \mathrm{l}$ of diluted Matrigel was added to the upper chamber, and incubated at $37^{\circ} \mathrm{C}$ for $4 \mathrm{~h}$ to solidify the gel. Cells in $100 \mu \mathrm{l}$ serum-free medium in the presence or absence of sulprostone were seeded in the upper chamber. Regular medium containing 10\% FBS was added in the lower chamber as the chemoattractant. After $24 \mathrm{~h}$ of incubation at $37^{\circ} \mathrm{C}$, the cells were fixed with ethanol and stained with $0.1 \%$ crystal violet for $30 \mathrm{~min}$. After washing the cells with PBS, the cells on the upper surface of the filter were mechanically removed with a cotton swab. The invading cells on the lower surface were solubilized with $300 \mu 110 \%$ acetic acid. The absorbance was measured at $570 \mathrm{~nm}$. These experiments were repeated three times, and three wells were used for each treatment.

Western blotting. At the end of each treatment, the cells were washed twice with ice-cold PBS and then sonicated on ice in a lysis buffer $(50 \mathrm{mM}$ Tris- $\mathrm{HCl} \mathrm{pH} 7.4,150 \mathrm{mM} \mathrm{NaCl}$, $0.5 \%$ sodium deoxycholate, $1 \%$ Nonidet P-40, $0.1 \%$ SDS, $1 \mathrm{mM}$ PMSF, sodium orthovanadate, sodium fluoride and aprotinin). Cell lysates were centrifuged at $12,000 \mathrm{x} \mathrm{g}$ for $10 \mathrm{~min}$ at $4^{\circ} \mathrm{C}$, and the supernatants were collected for western blotting. Protein concentration was measured using a protein assay. After boiling for $5 \mathrm{~min}$ in the loading buffer with $10 \%$ 2-mercaptoethanol, the samples containing $30 \mu \mathrm{g}$ protein were separated by SDS-PAGE and transferred onto nitrocellulose 
membranes. The membranes were blocked with $5 \%$ non-fat milk-TBST buffer for $1 \mathrm{~h}$ at room temperature and incubated with the corresponding primary antibodies overnight at $4{ }^{\circ} \mathrm{C}$ with gentle agitation. The membranes were washed in TBST and incubated for $2 \mathrm{~h}$ with secondary antibodies at room temperature. The signals were detected using ECL reagent and analyzed using Image Lab 4.0 analysis software from Bio-Rad.

RNA isolation and qPCR. Total RNA from the cultured cells was isolated using the TRIzol reagent according to the manufacturer's instructions. Reverse transcription was carried out with PrimeScript ${ }^{\mathrm{TM}}$ RT reagent kit according to the standard protocol. The primer sequences used were: EP3-4R, 5'-TGC ATCCAGCTCCACCTCCT-3' (forward) and 5'-GCAAAT TCAGGGAAGCAGGAATTGC-3' (reverse); EP3-5R, 5'-TGT TCGCCTGGCTTCACTGAACC-3' (forward) and 5'-AGA GCAGCTGGAGACAGCATTTGC-3' (reverse); EP3-6R, 5'-TGTTCGCCTGGCTTCACTGAACC-3' (forward) and 5'-TGTGATCCTGGCAGAAAGGCAGG-3' (reverse); EP3-7R, 5'-TGTGATCCTGGCAGAAAGGCAGG-3' (forward) and 5'-TTTGGGAGGTGGGTGTTTCTGTGA' (reverse); c-Myc, 5'-AGGCTATTCTGCCCATTT-3' (forward) and 5'-TCGTAGTCGAGGTCATAGTTC-3' (reverse); Snail, 5'-AAGGACCACCGCATCTCTAC-3' (forward) and 5'-CC AGCTCCTTGAAGCAGAAGA-3' (reverse); $\beta$-catenin, 5'-GC CAAGTGGGTGGTATAGAG-3', (forward) and 5'-TGGGAT GGTGGGTGTAAG-3' (reverse); GAPDH, 5'-TTCCAGGAG CGAGATCCCT-3' (forward) and 5'-CACCCATGACGAA CATGGG-3' (reverse). qPCR analysis was performed on a Roche LightCycler Nano instrument using FastStart Essential DNA Green Master Mix, and GAPDH was used as the endogenous control. The qPCR conditions were: pre-incubation at $95^{\circ} \mathrm{C}$ for $10 \mathrm{~min}(1 \mathrm{cycle})$ followed by denaturation of 40 cycles at $95^{\circ} \mathrm{C}$ for $20 \mathrm{sec}$, annealing at $60^{\circ} \mathrm{C}$ for $20 \mathrm{sec}$ and extension at $72^{\circ} \mathrm{C}$ for $20 \mathrm{sec}$. Treatments and conditions were performed in triplicate to calculate the statistical significance.

Statistical analysis. Date are presented as the means \pm SD. Statistical analysis was performed with the Student's t-test. $\mathrm{P}<0.05$ was considered statistically significant.

\section{Results}

Isoforms of EP3 receptors are overexpressed in cholangiocarcinoma and HEK $293 T$ cell. The CCLP1, HuCCT1 and HEK 293T cells were transfected with EP3-4R, EP3-5R, EP3-6R, EP3-7R or the pcDNA control plasmids and then selected by $\mathrm{G} 418$. The qPCR analysis results showed that mRNAs of EP3-4R, EP3-5R, EP3-6R and EP3-7R were increased significantly in pcDNA-EP3R-transfected cells respectively (Fig. 1A). Western blot analysis results showed that EP3 receptors were overexpressed in the pcDNA-EP3R transfected cells (Fig. 1B). The selected cells with increased EP3 proteins and mRNAs were used for subsequent experiments.

EP3 receptor isoforms play a key role in the proliferation of cholangiocarcinoma cells. The EP3R or control plasmids pcDNA3.1 transfected CCLP1 cells were examined for their response to treatment with the EP3 agonist, sulprostone. After treatment with different concentrations of sulprostone

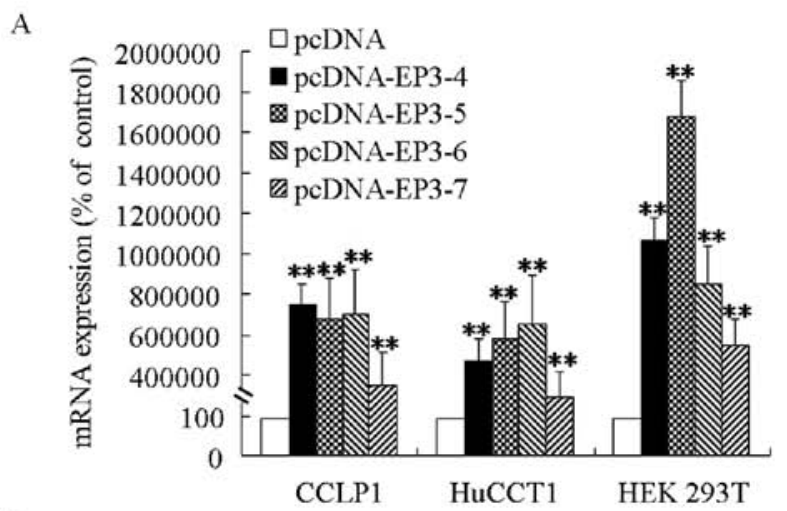

B

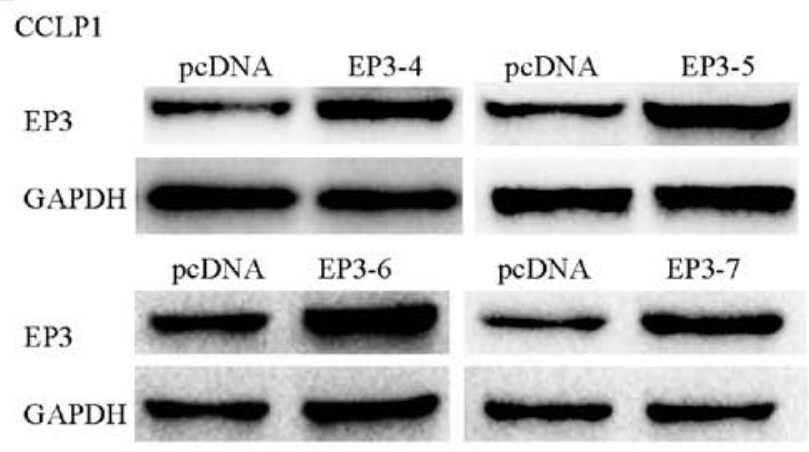

HuCCT1

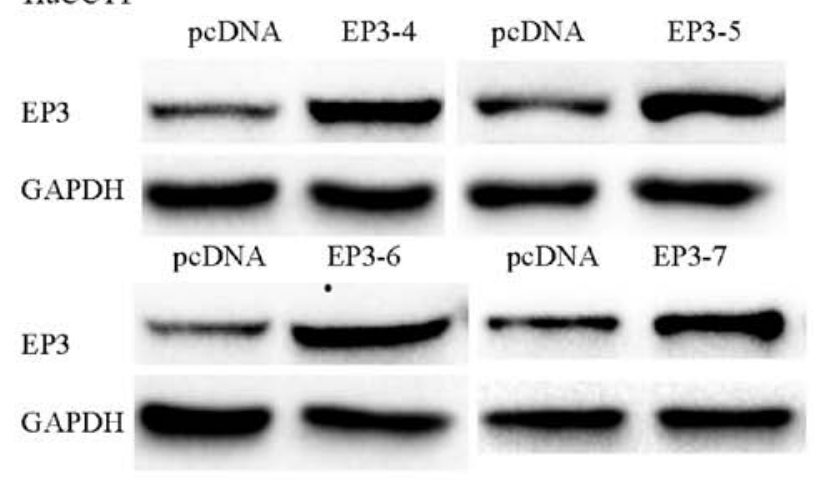

HEK 293T

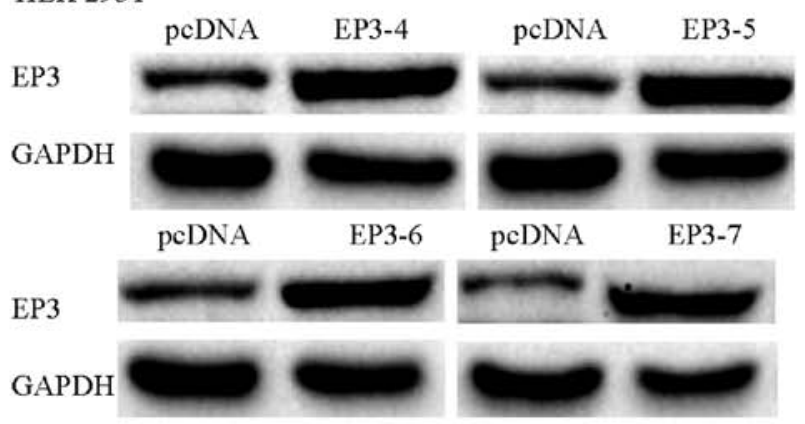

Figure 1. EP3 receptor isoforms mRNAs and proteins were overexpressed in pcDNA-EP3-transfected cells. (A) EP3 receptor isoforms mRNAs were overexpressed in CCLP1, HuCCT1 and HEK 293T cells. Cells were transfected with the EP3-4, EP3-5, EP3-6, EP3-7 or the pcDNA control plasmids. CCLP1 cells transfected with EP3R were selected by $500 \mu \mathrm{g} / \mathrm{ml} \mathrm{G} 418$. HuCCT1 cells were selected using 1,000 $\mu \mathrm{g} / \mathrm{ml} \mathrm{G} 418$ and HEK 293T cells by $200 \mu \mathrm{g} / \mathrm{ml} \mathrm{G} 418$. The expression of the EP3R isoforms mRNAs were confirmed by qPCR analysis. Levels of GAPDH served as the control. (B) EP3 receptor isoforms proteins were overexpressed in CCLP1, HuCCT1 and HEK 293T cells. The cells were transfected with the EP3-4, EP3-5, EP3-6, EP3-7 or the pcDNA control plasmids. The expression of the EP3R isoforms proteins were determined by western blotting with anti-EP3R antibody, and GAPDH as the loading control with anti-GAPDH antibody. ${ }^{* *} \mathrm{P}<0.01$, compared with the control. Data are presented as the mean $\pm \mathrm{SD}$ of three independent experiments. 


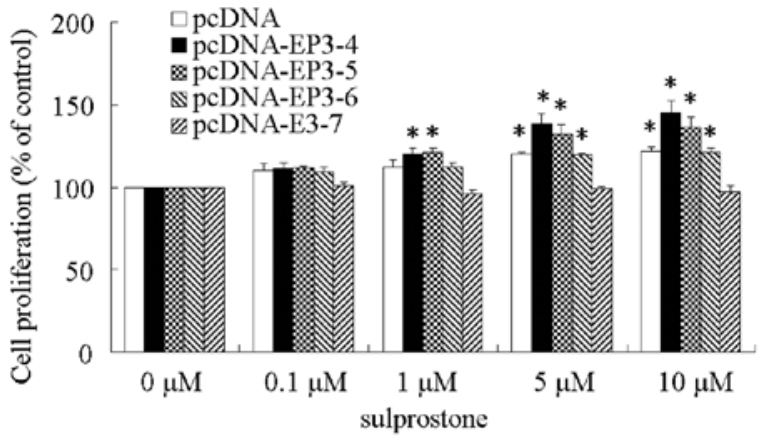

Figure 2. Effects of EP3 receptor isoforms on sulprostone induced CCLP1 cell proliferation. The EP3R- and pcDNA3.1-transfected CCLP1 cells $\left(1 \times 10^{4}\right)$ were seeded in 96 -well plates in 100- $\mu 1$ serum-supplemented medium for $24 \mathrm{~h}$. The cells were treated with the indicated concentrations with EP3R agonist sulprostone for $24 \mathrm{~h}$, and cell proliferation was assessed by using the cell proliferation reagent WST-8. ${ }^{*} \mathrm{P}<0.05$ compared with the control. The data were obtained from six individual experiments and are presented as the mean $\pm \mathrm{SD}$ as a percentage of the respective control. for $24 \mathrm{~h}$, the cell proliferation rate was detected by WST-8 analysis. The results showed that the proliferation of CCLP1 cells treated with sulprostone was increased compared with the control in pcDNA-, pcDNA-EP3-4-, pcDNA-EP3-5- and pcDNA-EP3-6-transfected cells. Of these, the effect of pcDNA-EP3-4-transfected cells was the most significant. pcDNA-EP3-7-transfected cells did not exert any effect on cell proliferation (Fig. 2). Similar results were observed in the HuCCT1 and HEK 293T cells (data not shown).

EP3 receptor isoforms mediate the migration of cholangiocarcinoma cells. The EP3Rs or control plasmids pcDNA3.1-transfected CCLP1 cells were examined to determine their response to treatment with sulprostone. Following treatment with $10 \mu \mathrm{M}$ sulprostone for $12 \mathrm{~h}$, the cell migration rate was detected by Transwell analysis. The results showed that the migration of CCLP1 cells treated with sulprostone was increased compared with the control in pcDNA-,
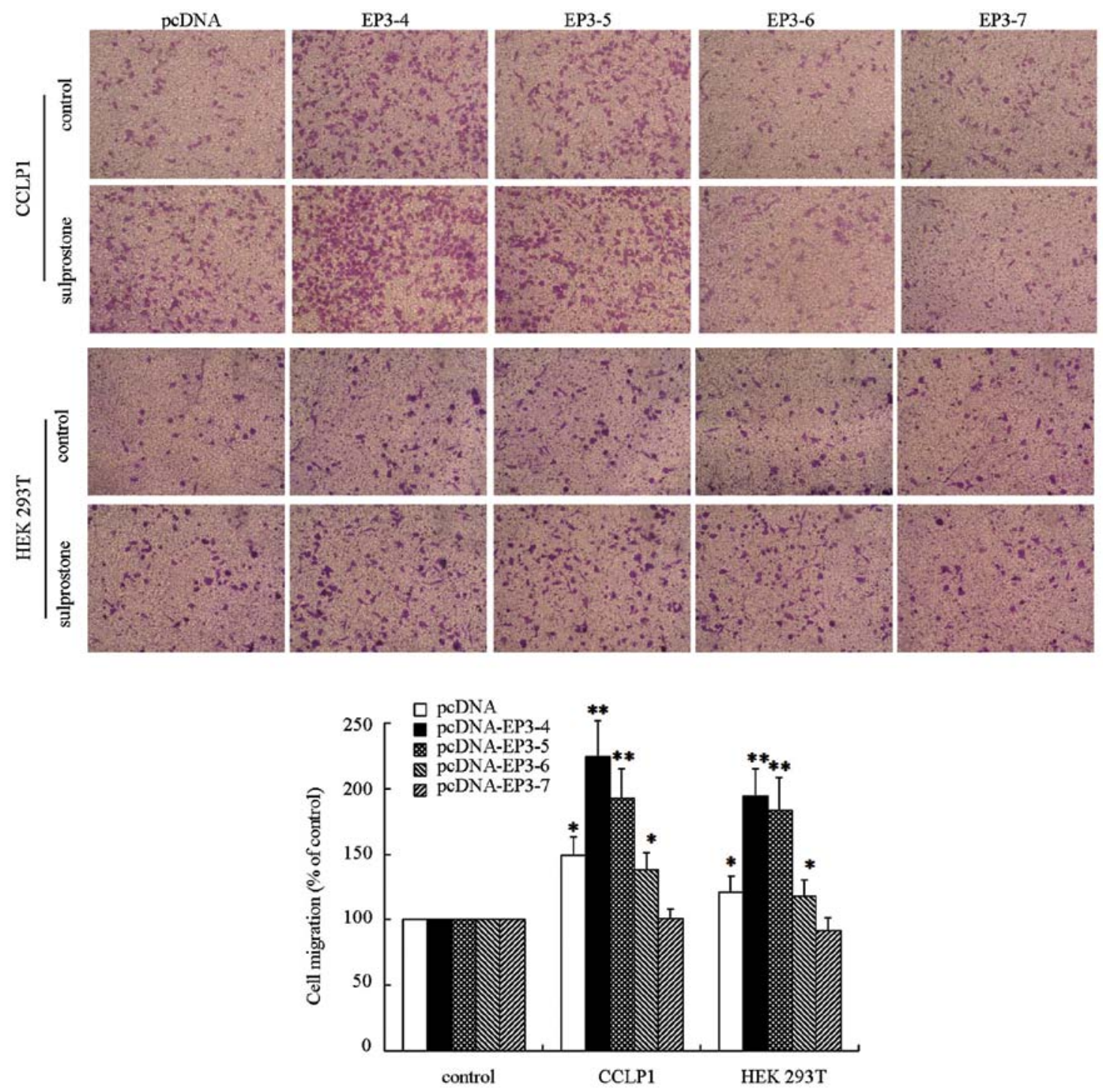

Figure 3. Effects of EP3 isoforms on sulprostone induced CCLP1 and HEK 293T cells migration. CCLP1 $\left(5 \times 10^{4}\right)$ and HEK $293 \mathrm{~T}\left(1 \times 10^{5}\right)$ cells transfected with pcDNA or EP3 receptor isoforms in $100 \mu \mathrm{l}$ serum-free medium were seeded in the upper chamber in the presence or absence of $10 \mu \mathrm{M}$ sulprostone, and the regular medium containing 10\% FBS was added to the lower chamber. After $12 \mathrm{~h}$, the cell migration assay was conducted. These experiments were repeated three times, and three wells were used for each treatment. Representative images of invaded cells from the independent groups are shown in the upper panels. ${ }^{*} \mathrm{P}<0.05,{ }^{* *} \mathrm{P}<0.01$ comparison with control. 

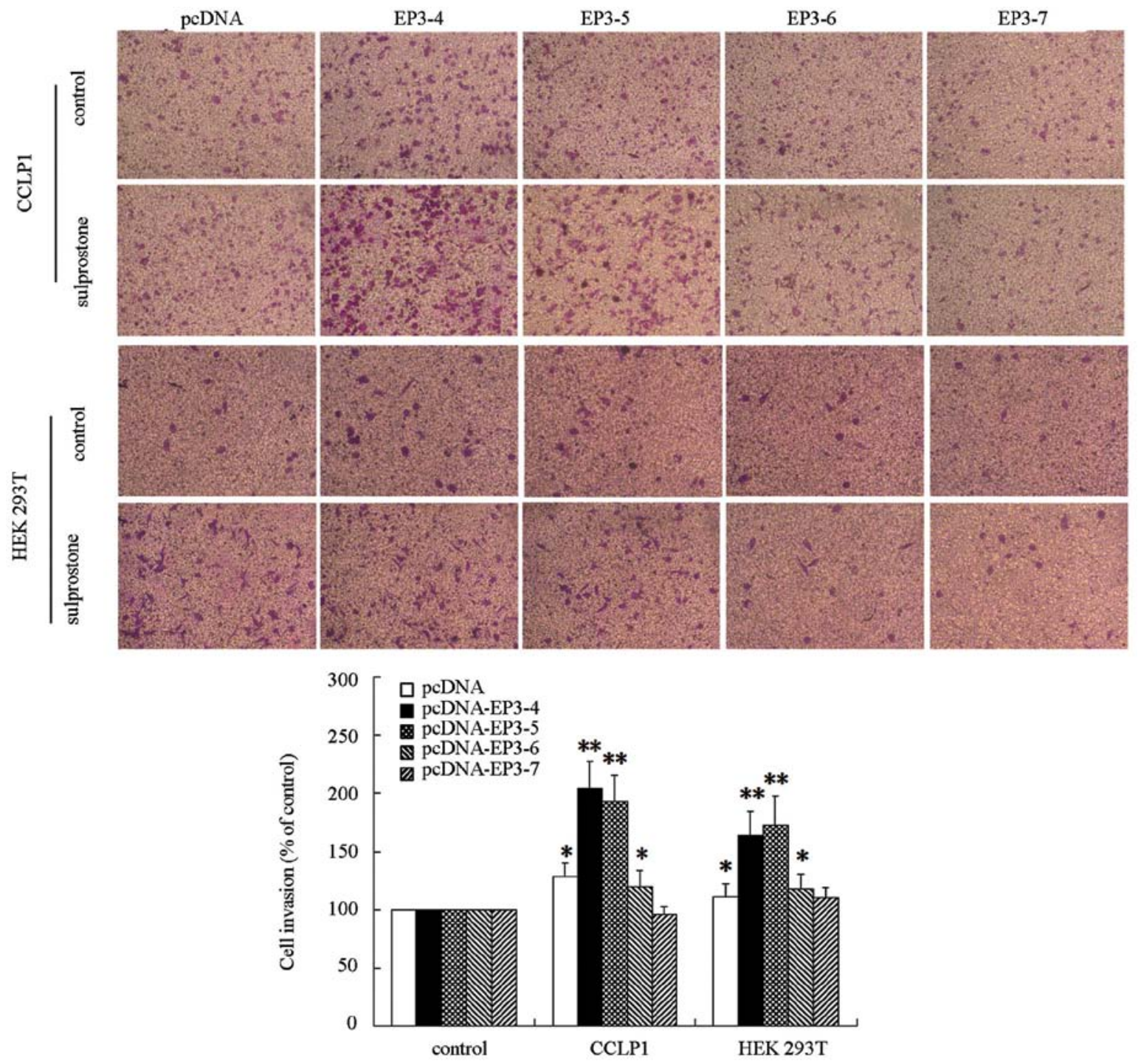

Figure 4. Effects of EP3 isoforms on sulprostone induced CCLP1 and HEK 293T cell invasion. The cell invasion assay was performed in Matrigel (1:6 for CCLP1 and 1:9.for HEK 293T)-coated Transwell chamber. CCLP1 $\left(5 \times 10^{4}\right)$ and HEK 293T (1x10 $)$ cells transfected with pcDNA or EP3 receptor isoforms in $100 \mu 1$ serum-free medium were seeded in the upper chamber in the presence or absence of $10 \mu \mathrm{M}$ sulprostone, and the regular medium containing $10 \%$ FBS was added to the lower chamber. After $24 \mathrm{~h}$, a cell invasion assay was conducted. These experiments were repeated three times, and three wells were used for each treatment. Representative images of invaded cells from independent groups are shown in the upper panels. ${ }^{*} \mathrm{P}<0.05,{ }^{* * *} \mathrm{P}<0.01$ comparison with the control.

pcDNA-EP3-4-, pcDNA-EP3-5- and pcDNA-EP3-6-transfected cells. Of these, the effect in pcDNA-EP3-4-transfected cells was the most significant. The pcDNA-EP3-7-transfected cells did not significantly affect the cell migration rate in the sulprostone treatment group compared with the control (Fig. 3). Similar results were observed in HuCCT1 (data not shown) and HEK 293 T cells (Fig. 3).

EP3 receptor isoforms are responsible for invasion in cholangiocarcinoma cells. The EP3R or control plasmid pcDNA3.1-transfected CCLP1 cells were examined to determine their response to treatment with sulprostone. Following treatment with $10 \mu \mathrm{M}$ sulprostone for $24 \mathrm{~h}$, the cell invasion rate was detected by Transwell analysis. The results showed that the invasion of CCLP1 cells treated with sulprostone was increased compared with the control in pcDNA-, pcDNAEP3-4-, pcDNA-EP3-5- and pcDNA-EP3-6-transfected cells. Of these, the effect in pcDNA-EP3-4-transfected cells was the most significant. The pcDNA-EP3-7-transfected cells did not significantly affect the cell invasion rate in the sulprostone treatment group compared with the control (Fig. 4). Similar results were observed in HuCCT1 (data not shown) and HEK 293 T cells (Fig. 4).

EP3-4 receptor pathway is involved in upregulation of PGE2-induced $\beta$-catenin. PGE2 enhanced the malignancy of cancer cells (8). Additionally, $\beta$-catenin has been reported to correlated with malignancy of cancer (25). We hypothesized that PGE2 promoted cholangiocarcinoma progression through the upregulation of $\beta$-catenin protein level. To evaluate this hypothesis, we treated pcDNA- and pcDNA-EP3-4-transfected CCLP1 cells with PGE2 with the indicated concentrations for $24 \mathrm{~h}$. The results showed that treatment of pcDNA- and pcDNA-EP3-4-transfected CCLP1 cells with PGE2 greatly increased the level of $\beta$-catenin protein and the effect on pcDNA-EP3-4-transfected CCLP1 cells was more significant 


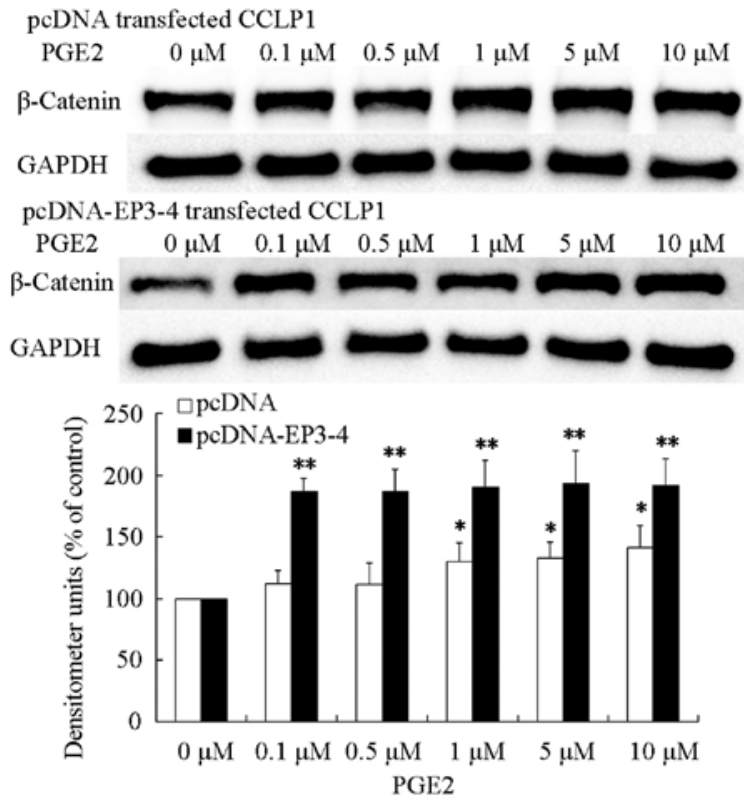

Figure 5. PGE2 upregulates $\beta$-catenin protein in CCLP1 cells. The pcDNA and pcDNA-EP3-4-transfected CCLP1 cells which cultured in serum-free medium for $24 \mathrm{~h}$ were treated with PGE2 at indicated concentration for $24 \mathrm{~h}$. $\beta$-catenin protein was determined by western blotting with anti- $\beta$-catenin antibody, and GAPDH as the loading control with anti-GAPDH antibody. Quantitative analysis of $\beta$-catenin expression level was carried out by calculating the the percentage of $\beta$-catenin protein and GAPDH levels from three different experiments. ${ }^{*} \mathrm{P}<0.05,{ }^{* *} \mathrm{P}<0.01$ compared with the control. Data are presented as the mean $\pm \mathrm{SD}$ of three independent experiments.

than that in pcDNA-transfected CCLP1 cells (Fig. 5). These findings indicated that PGE2 was able to upregulate the $\beta$-catenin protein level in CCLP1 cells.

To investigate the role of EP3R isoforms in the upregulation of $\beta$-catenin, the protein was determined in pcDNA-, pcDNA-EP3-4-, pcDNA-EP3-5-, pcDNA-EP3-6- and pcDNAEP3-7-transfected CCLP1 cells. As shown in Fig. 6A, $\beta$-catenin was significantly increased in pcDNA-EP3-4-transfected CCLP1 cells. Previous findings suggested that sulprostone promotes cholangiocarcinoma cell progression via the EP3-4 receptor, and PGE2 upregulated the $\beta$-catenin protein level. Thus, we hypothesized that PGE2 was able to upregulate $\beta$-catenin protein via the EP3-4 receptor. To evaluate this hypothesis, the pcDNA- and pcDNA-EP3-4-transfected CCLP1 cells were treated with the indicated concentrations of sulprostone for $24 \mathrm{~h}$. The results showed that treatment of pcDNA- or pcDNA-EP3-4-transtected CCLP1 cells with sulprostone greatly increased the level of $\beta$-catenin protein in a concentration-dependent manner (Fig. 6B). Pretreatment of pcDNA-EP3-4-transfected CCLP1 cells with EP3 selective antagonist L-798106 inhibited the upregulation of $\beta$-catenin induced by PGE2 (Fig. 6C). These results suggested that the EP3-4 receptor plays an important role in PGE2-induced $\beta$-catenin upregulation.

PGE2-associated $\beta$-catenin induces the upregulation of downstream c-Myc and Snail expression in cholangiocarcinoma cells. $\beta$-catenin was accumulated in the nucleus induced by PGE2 in cholangiocarcinoma cells (26). The accumulation of $\beta$-catenin in the nucleus induced transcription

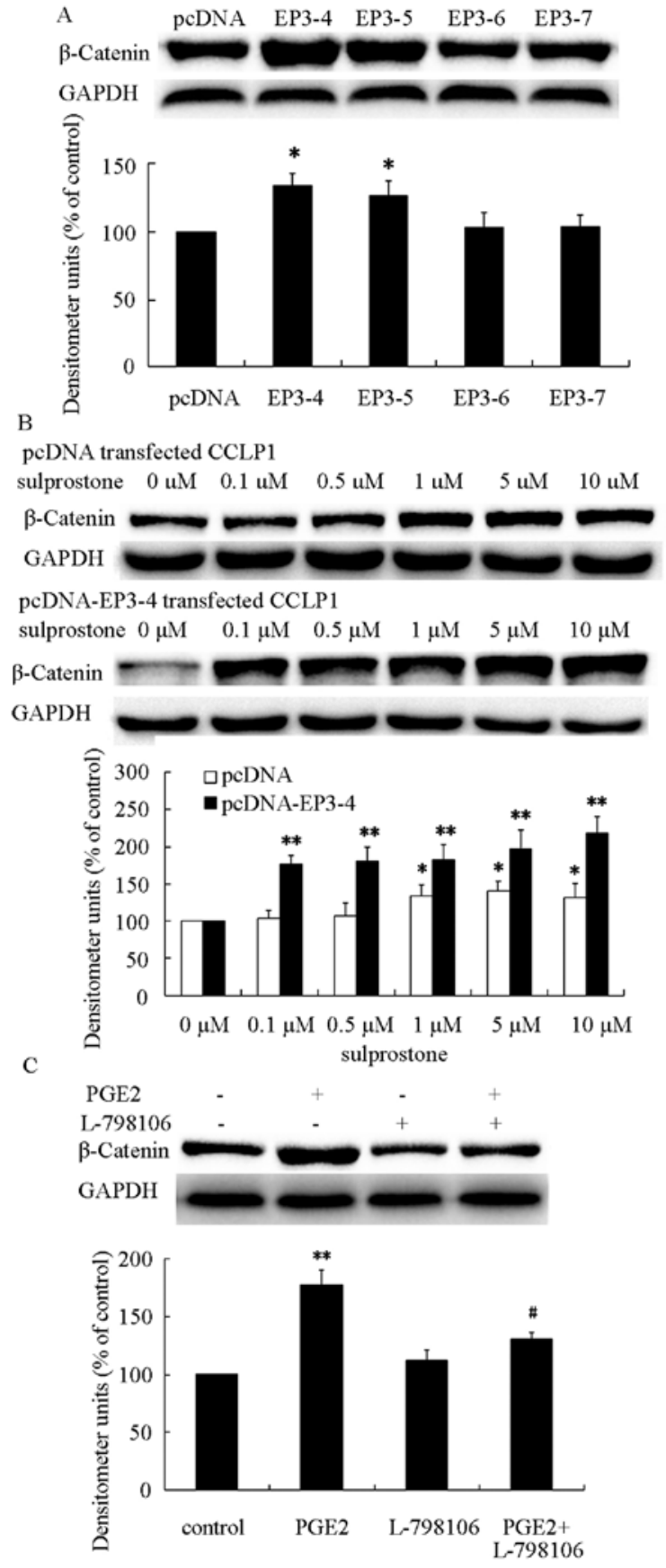

Figure 6. EP3-4 receptor is involved in PGE2 induced $\beta$-catenin expression. (A) $\beta$-catenin protein level in EP3Rs transfected CCLP1 cells. The pcDNA-, pcDNA-EP3-4-, pcDNA-EP3-5-, pcDNA-EP3-6- and pcDNA-EP37 -transfected CCLP1 cells were cultured. $\beta$-catenin expression level was determined by western blotting with anti- $\beta$-catenin antibody. GAPDH as the loading control was determined with anti-GAPDH antibody. (B) Effects of sulprostone on $\beta$-catenin upregulation in CCLP1 cells. The pcDNA- and pcDNA-EP3-4-transfected CCLP1 cells cultured in serum-free medium for $24 \mathrm{~h}$ were treated with sulprostone at the indicated concentration for $24 \mathrm{~h}$. $\beta$-catenin expression level was determined by western blotting with anti- $\beta$-catenin antibody. GAPDH as the loading control was determined with anti-GAPDH antibody. (C) Effects of EP3 receptor selective antagonist L-798106 on $\beta$-catenin expression induced by PGE2. The pcDNA-EP3-4-transfected CCLP1 cells cultured in serum-free medium for $24 \mathrm{~h}$ were pretreated with $10 \mu \mathrm{M} \mathrm{L}-798106$ for $1 \mathrm{~h}$, and then treated with $10 \mu \mathrm{M}$ PGE2 for $24 \mathrm{~h}$. $\beta$-catenin expression level was determined by western blotting with anti- $\beta$-catenin antibody, and GAPDH as the loading control with anti-GAPDH antibody. Quantitative analysis of the $\beta$-catenin expression level was carried out by calculating the percentage of $\beta$-catenin protein and GAPDH expression levels from three different experiments. ${ }^{*} \mathrm{P}<0.05$, ${ }^{* *} \mathrm{P}<0.01$ compared with the control; ${ }^{*} \mathrm{P}<0.05$ compared with the PGE2 treatment. Data are presented as the mean $\pm \mathrm{SD}$ of three independent experiments. 

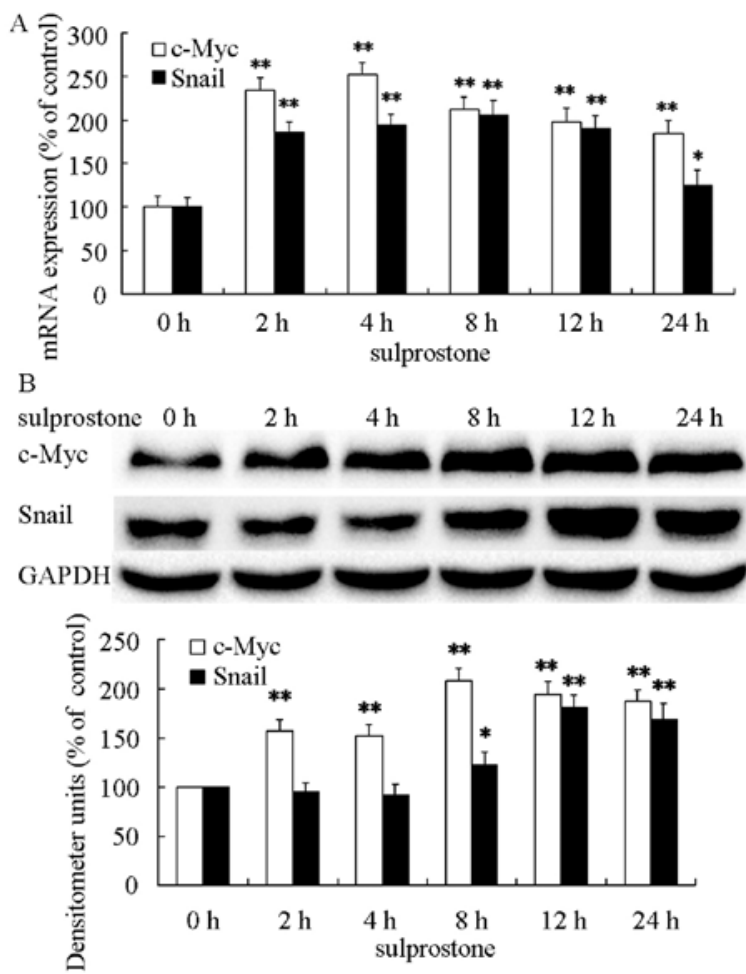

Figure 7. Sulprostone induces c-Myc and Snail expression. (A) Sulprostone upregulates c-Myc and Snail mRNAs in pcDNA-EP3-4-transfected CCLP1 cells. The pcDNA-EP3-4-transfected CCLP1 cells cultured in serum-free medium for $24 \mathrm{~h}$ were treated with $5 \mu \mathrm{M}$ sulprostone for the indicated time periods. The c-Myc and Snail mRNAs were determined by qPCR. GAPDH as the loading control was determined by qPCR. (B) Sulprostone upregulates c-Myc and Snail proteins in pcDNA-EP3-4-transfected CCLP1 cells. The pcDNA-EP3-4-transfected CCLP1 cells cultured in serum-free medium for $24 \mathrm{~h}$ were treated with $5 \mu \mathrm{M}$ sulprostone for the indicated time periods. The c-Myc and Snail proteins were determined by western blotting with antic-Myc and anti-Snail antibodies, and GAPDH as the loading control with anti-GAPDH antibody. Quantitative analysis of c-Myc and Snail expression levels were carried out by calculating the percentage of c-Myc, Snail proteins and GAPDH levels from three different experiments. ${ }^{*} \mathrm{P}<0.05,{ }^{* * *} \mathrm{P}<0.01$ compared with the control. Data are presented as the mean \pm SD of three independent experiments.

of important downstream target genes, such as $c-M y c$ and Snail $(27,28)$. The protein and mRMA levels were determined after pcDNA-EP3-4 transtected CCLP1 cells treated with $5 \mu \mathrm{M}$ sulprostone for the indicated time periods. The results showed that treatment of pcDNA-EP3-4-transfected CCLP1 cells with sulprostone increased the levels of c-Myc and Snail mRNAs and the levels of c-Myc and Snail proteins (Fig. 7).

The mechanism of the upregulation of $\beta$-catenin protein induced by PGE2. There are two main ways associated with the increase of $\beta$-catenin protein: upregulation of mRNA and downregulation of ubiquitin-dependent degradation. The degradation of $\beta$-catenin depends on $\beta$-catenin phosphorylation. Previous findings suggest that, PGE2 and sulprostone increased the level of $\beta$-catenin protein in a concentrationdependent manner. To confirm the $\beta$-catenin protein upregulation, the pcDNA-EP3-4-transfected CCLP1 cells were treated with $5 \mu \mathrm{M}$ sulprostone for the indicated time periods. The levels of $\beta$-catenin and phosphorylated $\beta$-catenin proteins were analyzed by western blotting and $\beta$-catenin mRNAs by qPCR. The results showed that treatment of
A

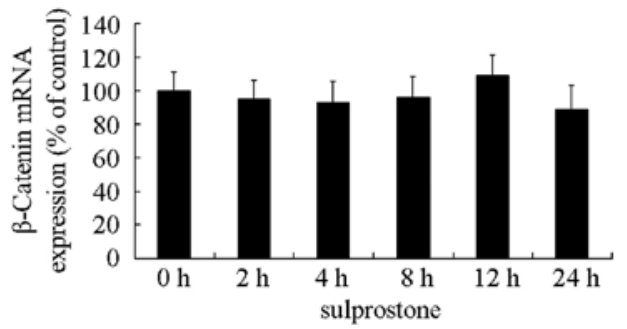

B

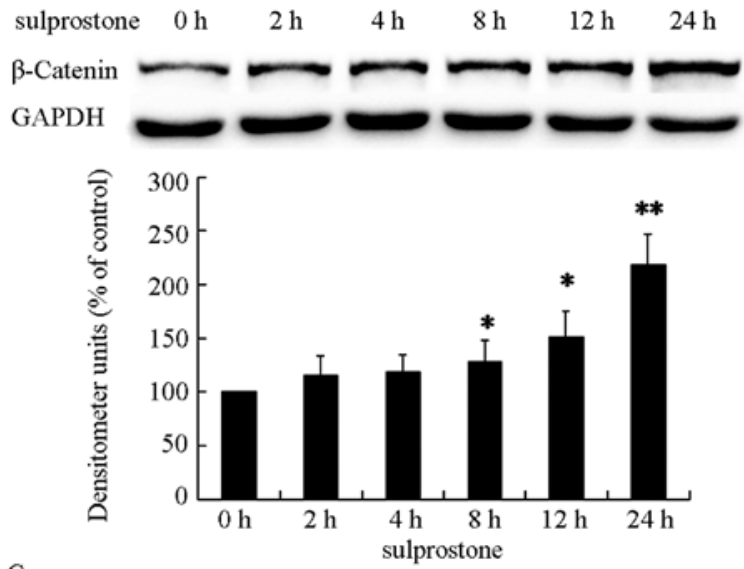

C

sulprostone $0 \mathrm{~min} \quad 5 \mathrm{~min} \quad 15 \mathrm{~min} \quad 30 \mathrm{~min} \quad 45 \mathrm{~min} \quad 60 \mathrm{~min}$ p- $\beta$-Catenin
$\beta$-Catenin
GAPDH

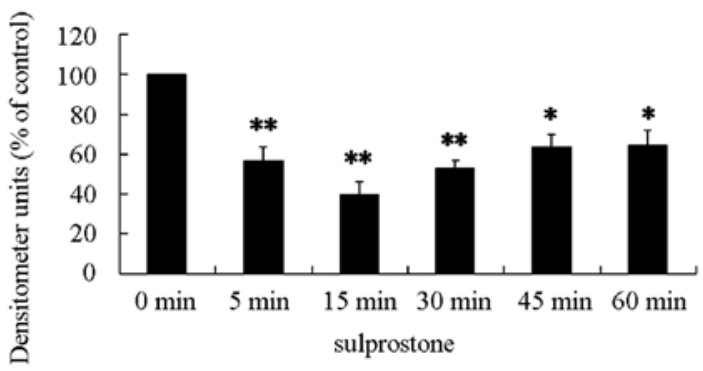

Figure 8. $\beta$-catenin protein upregulation induced by sulprostone in CCLP1 cells. (A) Effects of sulprostone on $\beta$-catenin mRNA level in pcDNAEP3-4-transfected CCLP1 cells. The pcDNA-EP3-4-transfected CCLP1 cells cultured in serum-free medium for $24 \mathrm{~h}$ were treated with sulprostone at $5 \mu \mathrm{M}$ for the indicated time points. The $\beta$-catenin mRNA was determined by qPCR. GAPDH as the loading control was determined by qPCR. (B) Sulprostone upregulates $\beta$-catenin protein in pcDNA-EP3-4-transfected CCLP1 cells. The pcDNA-EP3-4-transfected CCLP1 cells cultured in serum-free medium for $24 \mathrm{~h}$ were treated with sulprostone at $5 \mu \mathrm{M}$ for the indicated time points. $\beta$-catenin expression level was determined by western blotting with anti- $\beta$-catenin antibody, and GAPDH as the loading control with anti-GAPDH antibody. (C) Sulprostone downregulates the phosphorylation of $\beta$-catenin in pcDNA-EP3-4-transfected CCLP1 cells. The pcDNA-EP3-4-transfected CCLP1 cells cultured in serum-free medium for $24 \mathrm{~h}$ were treated with sulprostone at $5 \mu \mathrm{M}$ for the indicated time points. The phosphorylated- $\beta$-catenin protein level was determined by western blotting with anti-p- $\beta$-catenin antibody, and total $\beta$-catenin as the loading control with anti- $\beta$-catenin antibody. Quantitative analysis of protein and mRNA level was carried out from three different experiments. ${ }^{*} \mathrm{P}<0.05,{ }^{* *} \mathrm{P}<0.01$ compared with the control. Data are presented as the mean $\pm \mathrm{SD}$ of three independent experiments.

pcDNA-EP3-4-transfected CCLP1 cells with sulprostone increased the level of $\beta$-catenin protein and decreased the level of phosphorylated $\beta$-catenin protein in a time-dependent manner (Fig. 8B and C). However, the change of $\beta$-catenin 

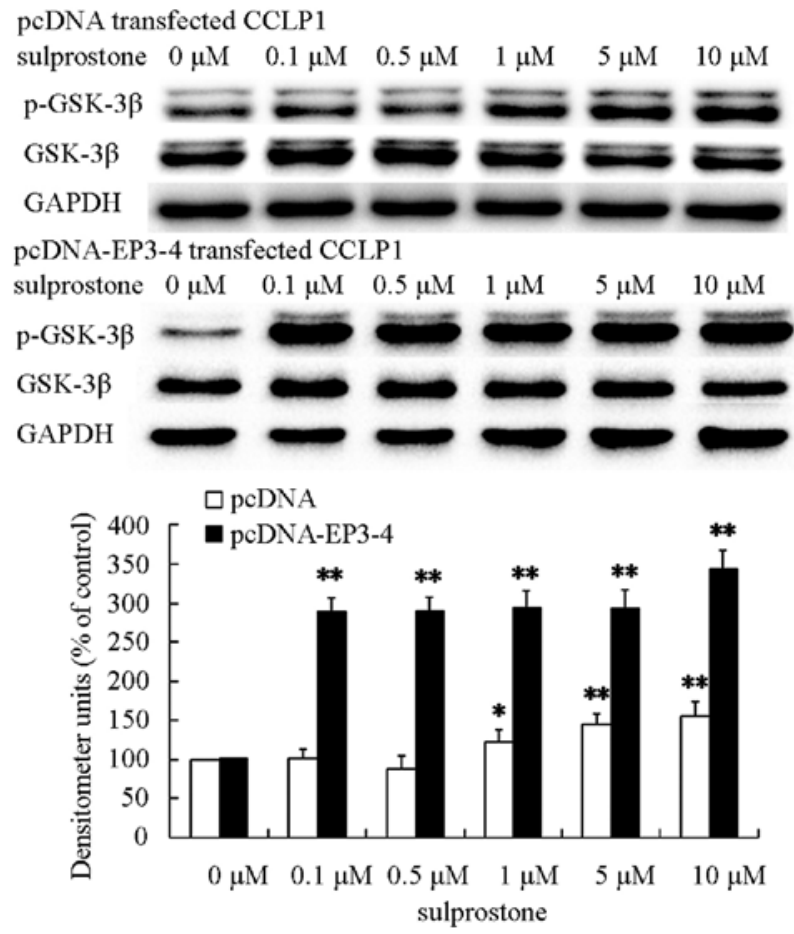

Figure 9. Sulprostone induces the phosphorylation of GSK-3 $\beta$ in CCLP1 cells. The pcDNA and pcDNA-EP3-4-transfected CCLP1 cells cultured in serum-free medium for $24 \mathrm{~h}$ were treated with sulprostone at the indicated concentration for $30 \mathrm{~min}$. Phosphorylated-GSK-3 $\beta$ and GSK- $3 \beta$ expression was determined by western blotting with anti-p-GSK-3 $\beta$ and antiGSK-3 $\beta$ antibodies. GAPDH was determined with anti-GAPDH antibody. Quantitative analysis of the p-GSK- $3 \beta$ protein level was carried out by calculating the percentage of $\mathrm{p}-\mathrm{GSK}-3 \beta$ and GSK-3 $\beta$ protein levels from three different experiments. ${ }^{*} \mathrm{P}<0.05,{ }^{* *} \mathrm{P}<0.01$ compared with the control. Data are presented as the mean $\pm \mathrm{SD}$ of three independent experiments.

mRNA was not observed in the experiment (Fig. 8A). These results indicated that the degradation of $\beta$-catenin is the main reason for the upregulation of $\beta$-catenin induced by PGE2.

PI3K/AKT and GSK-3 $\beta$ are involved in the upregulation of $\beta$-catenin induced by PGE2. GSK-3 $\beta$ associates in a complex with $\beta$-catenin, then $\beta$-catenin is phosphorylated and targeted for degradation (30). The phosphorylation of GSK-3 $\beta$ on serine 9 inhibits its kinase activity. Therefore, the phosphorylation of GSK- $3 \beta$ results in the loss of phosphorylation of $\beta$-catenin and the accumulation of $\beta$-catenin protein. Previous findings suggested that loss phosphorylation of $\beta$-catenin was induced by PGE2. Thus, we postulated that PGE2 could upregulate $\beta$-catenin protein via GSK-3 $\beta$. To evaluate this hypothesis, the pcDNA- and pcDNA-EP3-4-transfected CCLP1 cells were treated at the indicated concentrations of sulprostone for $30 \mathrm{~min}$. The levels of GSK-3 $\beta$ and phosphorylated- GSK-3 $\beta$ proteins were determined by western blotting. The results showed that treatment of pcDNA- and pcDNAEP3-4-transfected CCLP1 cells with sulprostone increased the levels of phosphorylated GSK-3 $\beta$ proteins (Fig. 9).

It has been reported that AKT is the kinase responsible for the phosphorylation of GSK-3 $\beta(31,32)$. We postulated that PGE2 upregulated $\beta$-catenin protein and inactivated GSK-3 $\beta$ via AKT. To evaluate this hypothesis, the pcDNAand pcDNA-EP3-4-transfected CCLP1 cells were treated

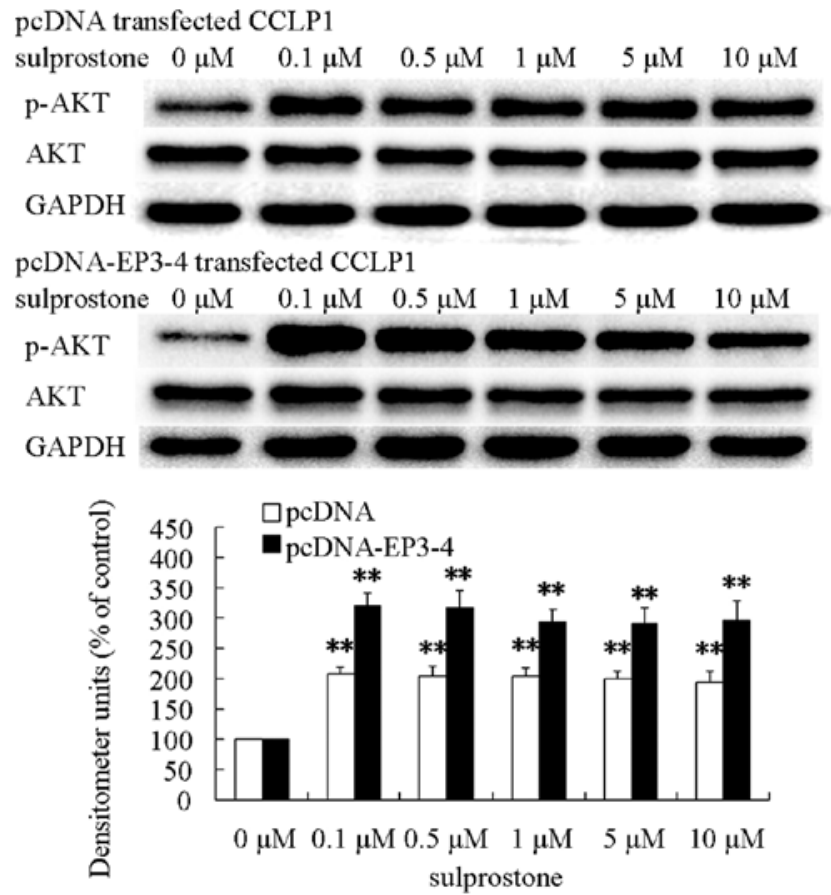

Figure 10. Sulprostone induces the phosphorylation of AKT in CCLP1 cells. The pcDNA and pcDNA-EP3-4-transfected CCLP1 cells cultured in serum-free medium for $24 \mathrm{~h}$ were treated with sulprostone at the indicated concentrations for $30 \mathrm{~min}$. Phosphorylated-AKT and AKT expression was determined by western blotting with anti-p-AKT and anti-AKT antibodies. GAPDH was determined with anti-GAPDH antibody. Quantitative analysis of the p-AKT level was carried out by calculating the percentage of p-AKT and AKT protein levels from three different experiments. ${ }^{* *} \mathrm{P}<0.01$ compared with the control. Data are presented as the mean $\pm \mathrm{SD}$ of three independent experiments.

at the indicated concentrations of sulprostone for $30 \mathrm{~min}$. The levels of AKT and phosphorylated AKT proteins were analyzed by western blotting. The results showed that treatment of pcDNA- and pcDNA-EP3-4-transfected CCLP1 cells with sulprostone increased the levels of phosphorylated-AKT proteins (Fig. 10).

The pcDNA-EP3-4-transfected CCLP1 cells were pretreated with the PI3K/AKT inhibitor LY-294002 or GSK-3 $\beta$ inhibitor $\mathrm{LiCl}$, and then treated with sulprostone. The $\beta$-catenin expression level was determined by western blotting. It was also shown that pretreatment of pcDNA-EP3-4-transfected CCLP1 cells with LY-294002 inhibited the upregulation of $\beta$-catenin protein and with $\mathrm{LiCl}$ promoted the upregulation of $\beta$-catenin protein induced by sulprostone (Fig. 11).

These results indicated that the upregulation of $\beta$-catenin induced by PGE2 is mediated through the activation of PI3K/AKT and GSK-3 $\beta$.

EGFR and Src are involved in AKT activation. EGFR and Src have been reported to be downstream of the EP receptors, and are important for progression of cancer $(7,8,33)$. Therefore, we hypothesized that upregulation of $\beta$-catenin induced by sulprostone was mediated by EGFR and Src. To evaluate this hypothesis, the pcDNA- and pcDNA-EP3-4-transfected CCLP1 cells were treated with the indicated concentrations of sulprostone for $45 \mathrm{~min}$. The levels of EGFR and phosphorylated-EGFR proteins were analyzed by western blotting. 


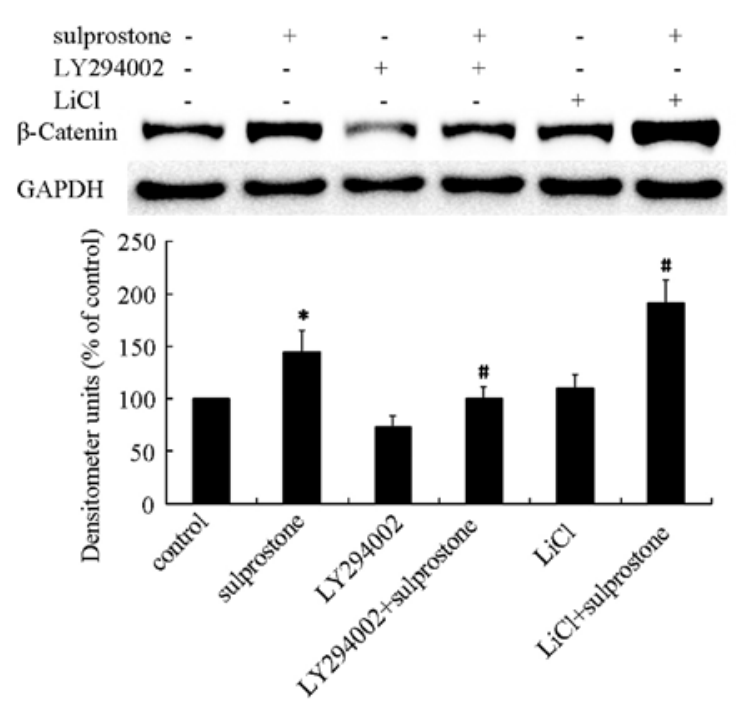

Figure 11. Effects of PI3K/AKT antagonist LY294002 and GSK-3 $\beta$ antagonist $\mathrm{LiCl}$ on $\beta$-catenin upregulation induced by sulprostone. The pcDNA-EP3-4-transfected CCLP1 cells cultured in serum-free medium for $24 \mathrm{~h}$ were pretreated with $10 \mu \mathrm{M} \mathrm{LY} 294002$ or $40 \mathrm{mM} \mathrm{LiCl}$ for $1 \mathrm{~h}$, and then treated with $5 \mu \mathrm{M}$ sulprostone for $24 \mathrm{~h}$. The $\beta$-catenin expression level was determined by western blotting with anti- $\beta$-catenin antibody, and GAPDH as the loading control with anti-GAPDH antibody. Quantitative analysis of the $\beta$-catenin expression level was carried out by calculating the percentage of $\beta$-catenin protein and GAPDH levels from three different experiments. " $\mathrm{P}<0.05$, compared with the control. ${ }^{\text {}} \mathrm{P}<0.05$ compared with the sulprostone treatment. Data are presented as the mean $\pm \mathrm{SD}$ of three independent experiments.

The results showed that treatment of pcDNA- and pcDNAEP3-4-transfected CCLP1 cells with sulprostone increased the levels of phosphorylated-EGFR proteins (Fig. 12). The pcDNA-EP3-4-transfected CCLP1 cells were pretreated with Src inhibitor PP2 or EGFR inhibitor AG1478, and then treated with sulprostone. The phosphorylation of AKT was determined by western blotting after $30 \mathrm{~min}$ of treatment with sulprostone and $\beta$-catenin was determined after $24 \mathrm{~h}$ of treatment with sulprostone. Pretreatment of pcDNAEP3-4-transfected CCLP1 cells with PP2 or AG1478 inhibited the phosphorylation of AKT and the upregulation of $\beta$-catenin protein (Fig. 13). These results indicated that PGE2 upregulates $\beta$-catenin expression is mediated through the activation of Src and EGFR.

\section{Discussion}

Prostaglandin E2 (PGE2) appears to participate in the development of inflammatory reactions and in oncogenesis $(3,4)$. Our previous results revealed that PGE2 significantly enhanced the cell proliferation, migration and invasion in cholangiocarcinoma cells, and several signaling pathways were identified such as the upregulation of MMP-2 expression through the CREB pathway (11), upregulaion of FBP1 expression through the cAMP/PKA pathway (12) and stimulation of Erk through the phosphorylation of EGFR (34). PGE2 significantly promoted hepatocellular carcinoma cell proliferation and invasion by upregulating the expression of Snail (6,7), YB-1 (8), c-Myc (9), $\beta 1$-integrin (10) and other factors. Additionally, PGE2 promoted cell proliferation and invasion in other types of cancer (13-15).

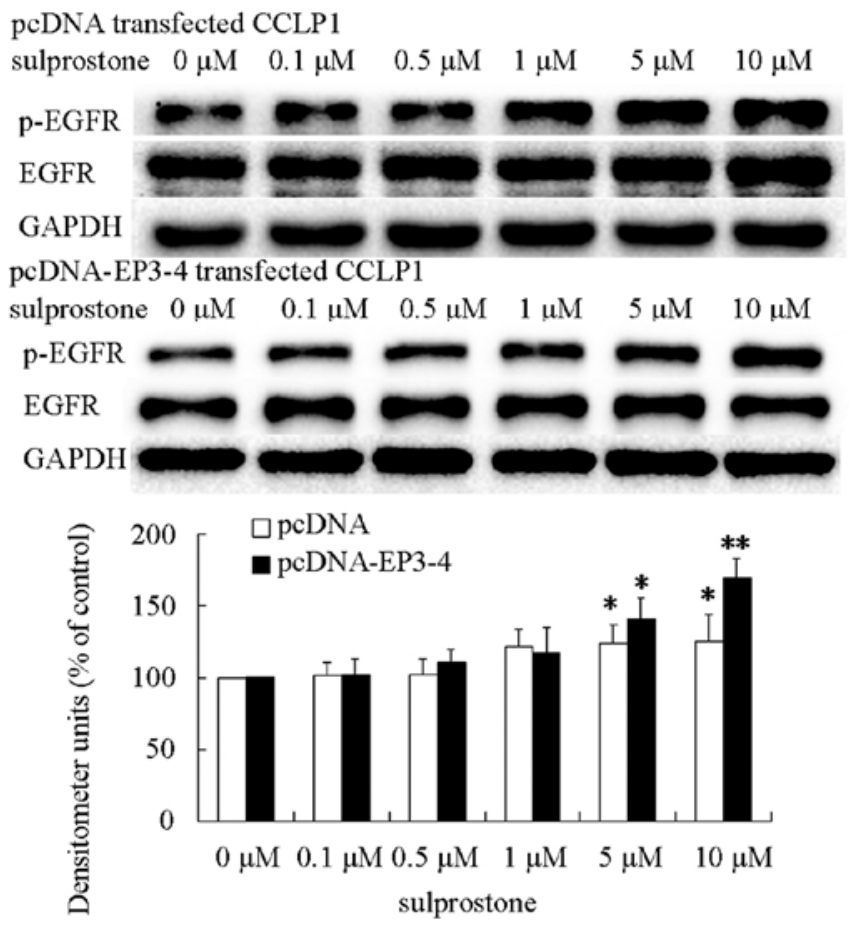

Figure 12. Sulprostone induces the phosphorylation of EGFR in CCLP1 cells. The pcDNA- and pcDNA-EP3-4-transfected CCLP1 cells cultured in serum-free medium for $24 \mathrm{~h}$ were treated with sulprostone at the indicated concentrations for $45 \mathrm{~min}$. Phosphorylated-EGFR and EGFR expression was determined by western blotting with anti-p-EGFR and anti-EGFR antibodies GAPDH was determined with anti-GAPDH antibody. Quantitative analysis of the p-EGFR protein level was carried out by calculating the percentage of p-EGFR and EGFR protein expression levels from three different experiments. ${ }^{*} \mathrm{P}<0.05,{ }^{* *} \mathrm{P}<0.01$ compared with the control. Data are presented as the mean $\pm \mathrm{SD}$ of three independent experiments.

The action of PGE2 is mediated by four $G$ protein-coupled receptors (GPCRs): EP1, EP2, EP3 and EP4 (35), which activate multiple signal transduction pathways leading to downstream responses. The EP1 receptor mainly couples to Gaq protein and upregulates the level of intracellular $\mathrm{Ca}^{2+}$. The EP2 and EP4 receptors couple to Gas protein, activate adenylate cyclase (AC) and increase the production of cyclic AMP (cAMP). However, the EP3 receptor which couples to $\mathrm{G}$ protein is more complicated $(12,16)$. Among EP receptors, EP3 is unique in that alternative mRNA splicing leads to multiple isoforms including EP3 subtype isoforms 4, 5, 6, 7, and 8 (also known as EP3-4, $-5,-6,-7$ and-8). In a previous study (12), EP3-4, -5, -6 and-7 receptors were observed in CCLP1 and HuCCT1 cells. Those results indicated that, EP3-4 and EP3-5 receptors significantly promoted cholangiocarcinoma cell proliferation, migration and invasion, whereas no significant increase in EP3-6 and EP3-7 receptors was discernable. EP3 isoforms may mediate different intracellular responses to PGE2, contributing to the different roles played by the progression of cancer. EP3 isoform receptors that promote cancer progression may be coupled with Gas and stimulate the AC-cAMP-PKA pathway (12). EP3 isoform receptors that exhibit no significant increase in cancer progression may be coupled with Gai and downregulate the AC-cAMP-PKA pathway (36). All the EP3 isoforms share a common $\mathrm{N}$-terminal sequence, which includes hormone binding and membrane spanning regions. However, each isoform has a unique amino acid composition in the C-terminal 

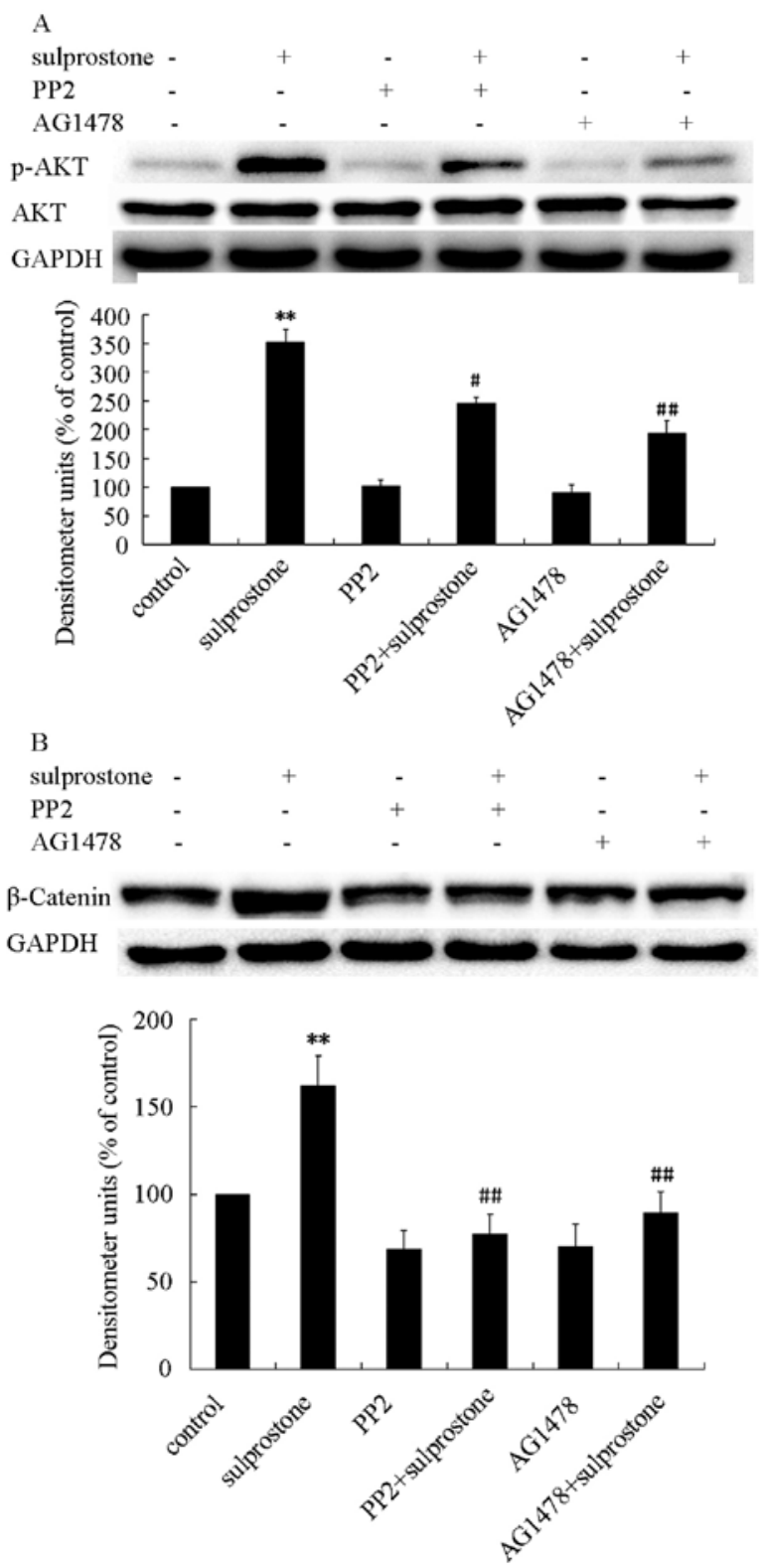

Figure 13. Effects of Src inhibitor PP2 and EGFR inhibitor AG1478 on AKT activation and $\beta$-catenin upregulation induced by sulprostone in CCLP1 cells. (A) The pcDNA-EP3-4-transfected CCLP1 cells cultured in serum-free medium for $24 \mathrm{~h}$ were pretreated with $10 \mu \mathrm{M}$ PP2 or $5 \mu \mathrm{M}$ AG1478 for $1 \mathrm{~h}$, and then treated with $0.1 \mu \mathrm{M}$ sulprostone for $30 \mathrm{~min}$. The p-AKT and AKT protein level was determined by western blotting with anti-p-AKT and antiAKT antibodies. GAPDH was determined with anti-GAPDH antibody. (B) Effects of PP2 and AG1478 on $\beta$-catenin upregulation induced by sulprostone in CCLP1 cells. The pcDNA-EP3-4-transfected CCLP1 cells cultured in serum-free medium for $24 \mathrm{~h}$ were pretreated with $10 \mu \mathrm{M} \mathrm{PP} 2$ or $5 \mu \mathrm{M}$ AG1478 for $1 \mathrm{~h}$, and then treated with $5 \mu \mathrm{M}$ sulprostone for $24 \mathrm{~h}$. The $\beta$-catenin protein level was determined by western blotting with anti- $\beta$-catenin antibody. GAPDH as the loading control was determined with anti-GAPDH antibody. Quantitative analysis of the p-AKT protein level was carried out by calculating the percentage of $\mathrm{p}-\mathrm{AKT}$ and AKT protein levels from three different experiments. Quantitative analysis of the $\beta$-catenin expression level was carried out by calculating the percentage of $\beta$-catenin and GAPDH protein levels from three different experiments. ${ }^{* *} \mathrm{P}<0.01$ compared with the control. ${ }^{*} \mathrm{P}<0.05$, ${ }^{\# \#} \mathrm{P}<0.01$ compared with the sulprostone treatment. Data are presented as the mean \pm SD of three independent experiments.

region which regulates the intracellular location and plays a key role in G-protein coupling. These unique sequences in the C-terminal domains may allow each EP3 isoform to localize to different areas within the cell and trigger different intracellular signaling pathways in response to PGE2. Evidence of different signal transduction pathways and the regulation of gene expression among different EP3 receptor isoforms has also been previously demonstrated $(12,17)$. There are EP1, EP2, EP4 and four EP3 isoforms receptors involved in cholangiocarcinoma progression, and some receptors play a positive role while others do not. The reason that some EP3 isoforms couple with Gai and do not promote cholangiocarcinoma cell growth and invasion may due to the fact that they are negative regulatory receptors that downregulate the function of other EP receptors.

$\beta$-catenin is critically responsible for epithelial cell-cell adhesion (37), and plays a key role in several developmental and pathologic processes including early embryonic development (38), fibrosis (39-42), cystic disease (43), renal failure (44) and cancer. For example, the expression level of $\beta$-catenin has been shown to correlate with progression in colorectal (18), cervical (19), prostate (20), renal cell carcinoma $(45,46)$, hepatocellular carcinoma $(47,48)$, cholangiocarcinoma (26) and several other types of tumors. PGE 2 and $\beta$-catenin are involved in cholangiocarcinoma progression, and our studies confirm that PGE2 upregulates the $\beta$-catenin protein through the EP3-4 receptor. There are two main ways leading to the increase of $\beta$-catenin protein, upregulation of mRNA and downregulation of ubiquitin-dependent protein degradation. The ubiquitin-dependent degradation is caused by phosphorylation of $\beta$-catenin at Ser33, Ser37, and Thr41 or coupled with Ebi which transfers the ubiquitin of ubiquitin-conjugating enzymes UcbH5 to $\beta$-catenin. Our results show that the downregulation of ubiquitin-dependent degradation induced by $\beta$-catenin phosphorylation is the main reason for the upregulation of $\beta$-catenin induced by PGE2 instead of an increasing in mRNA expression. The complex including Axin, APC, Amer1, CK $1 \alpha$ Glycogen synthase kinase $3 \beta$ (GSK-3 $\beta$ ) and $\beta$-catenin was separated when $\beta$-catenin phosphorylated at Ser33, Ser37 and Thr41. As a scaffold protein, Axin, a plurality of the protein interaction site, can combine APC Amer1, CK1 $\alpha$ GSK-3 $\beta$ and $\beta$-catenin together. The main functions of APC and Amer1 enhanced the affinity of $\beta$-catenin and the complex (49). Based on the phosphorylation of $\beta$-catenin at Ser45 induced by CK $1 \alpha$, GSK-3 $\beta$ can phosphorylate $\beta$-catenin at Thr41, Ser37, and Ser33, which is discerned by $\beta$-TrCP and lead to $\beta$-catenin degradation. When $\beta$-catenin phosphorylation was downregulated by PGE2 at Ser33, Ser37 and Thr41, the ubiquitin-dependent degradation was inhibited, and $\beta$-catenin accumulated in the cytoplasm forming a complex with the transcription factor, lymphoid enhancing factor-1/T-cell factor, which is subsequently transported into the cell nucleus (50). This transcription complex activates the expression of downstream target genes, including c-Jun, c-Fos, c-Myc (27), Snail (28), cyclin D1 (29) and survivin, resulting in abnormal cell proliferation and cell carcinogenesis. Our results show that the expression of c-Myc and Snail which is associated with hepatic carcinoma progression observed in previous studies $(6,9)$ also induced an increase of the EP3 receptor agonist.

The phosphorylation of GSK-3 $\beta$ at Ser 9 inhibits its kinase activity and results in the accumulation of $\beta$-catenin protein (30). Our results indicate that the phosphorylation of GSK-3 $\beta$ and AKT is responsible for the upregulation of $\beta$-catenin induced by PGE2. Phosphatidylinositol 3-kinase 
(PI3K) is composed of the p85 regulatory subunit and the p110 catalytic subunit. When PI3K is activated, the p85 subunit is recruited and the p110 subunit is activated. Activated PI3K leads to the consequent activation of PDK and AKT. AKT is the important kinase responsible for the phosphorylation of GSK-3 $\beta(31,32)$.

EP3-4 receptor activated by PGE2 may couple to Gas protein and activate the AC/PKA pathway (12). Based on this pathway, treatment of CCLP1 cells with the AC inhibitor SQ22536 and the PKA inhibitor H89 inhibit the effects of EP3 receptor agonist-induced $\beta$-catenin expression. However, those results have not been observed in our experiments (data not shown). This observation suggests that the Gas/AC/PKA pathway may not be responsible for the EP3-4 receptor-mediated $\beta$-catenin protein upregulation.

EP receptors may also modulate activation of the epidermal growth factor receptor (EGFR) $(33,34,51)$. In our previous studies, the EP1, EP2 and EP4 receptors activated the EGFR by forming the complex with EGFR and Src (6-8). The EGFR is a transmembrane tyrosine kinase that belongs to the HER/ErbB protein family. EGFR controls a variety of biological responses such as cell proliferation and migration. These effects are mediated via activation of the downstream molecules, including the PI3K/AKT pathway (52). It was reported that EGFR mediates Grb2 associated binder protein 1 (Gab1) activation in cultured rat hepatocytes. Depletion of Gabl, using siRNA, decreased AKT activation (53). In breast and lung cancer cell lines, PGE2 was associated with activated AKT, through increases in the EGFR-Gabl complexes $(54,55)$. It was also reported that the EP receptor was able to bind to EGFR directly (33). Our results indicate that PGE2 stimulated EGFR leading to the upregulation of $\beta$-catenin. Thus that the ligand combines its specific receptor is not the only manner in which to conduct signaling. The combination and interreaction between two receptors may also mediate the function of the ligand, such as the binding and interaction of EPR and EGFR.

To the best of our knowledge, this is the first study detailing the function of EP3 isoforms in human cholangiocarcinoma cells. The results also show that PGE2 upregulated the $\beta$-catenin protein through the EP3-4R/Src/EGFR/AKT/GSK-3 $\beta$ pathway. Our findings reveal the role of EP3 isoforms in promoting cholangiocarcinoma cell growth and invasion and a new theory that interaction between two receptors can conduct cell signaling without the stimulation of a specific ligand.

\section{Acknowledgements}

The present study was supported by the National Natural Science Foundation of China (81172003) and a project funded by the Priority Academic Program Development of Jiangsu Higher Education Institutions (PAPD).

\section{References}

1. Zou S, Li J, Zhou H, Frech C, Jiang X, Chu JS, Zhao X, Li Y, Li Q, Wang H, et al: Mutational landscape of intrahepatic cholangiocarcinoma. Nat Commun 5: 5696, 2014

2. Ali SM, Clark CJ, Mounajjed T, Wu TT, Harmsen WS, Reid-Lombardo KM, Truty MJ, Kendrick ML, Farnell MB, Nagorney DM, et al: Model to predict survival after surgical resection of intrahepatic cholangiocarcinoma: the Mayo Clinic experience. HPB (Oxford) 7: 244-250, 2014.
3. Montrose DC, Nakanishi M, Murphy RC, Zarini S, McAleer JP, Vella AT and Rosenberg DW: The role of PGE in intestinal inflammation and tumorigenesis. Prostaglandins Other Lipid Mediat 116-117C: 26-36, 2014.

4. Bai XM, Zhang W, Liu NB, Jiang H, Lou KX, Peng T, Ma J, Zhang L, Zhang $\mathrm{H}$ and Leng J: Focal adhesion kinase: Important to prostaglandin $\mathrm{E}_{2}$-mediated adhesion, migration and invasion in hepatocellular carcinoma cells. Oncol Rep 21: 129-136, 2009.

5. Bai XM, Jiang H, Ding JX, Peng T, Ma J, Wang YH, Zhang L, Zhang $\mathrm{H}$ and Leng J: Prostaglandin $\mathrm{E}_{2}$ upregulates survivin expression via the EP1 receptor in hepatocellular carcinoma cells. Life Sci 86: 214-223, 2010.

6. Zhang M, Zhang H, Cheng S, Zhang D, Xu Y, Bai X, Xia S, Zhang L, Ma J, Du M, et al: Prostaglandin E2 accelerates invasion by upregulating Snail in hepatocellular carcinoma cells. Tumour Biol 35: 7135-7145, 2014.

7. Cheng SY, Zhang H, Zhang M, Xia SK, Bai XM, Zhang L, Ma J, Rong R, Wang YP, Du MZ, et al: Prostaglandin $\mathrm{E}_{2}$ receptor EP2 mediates Snail expression in hepatocellular carcinoma cells. Oncol Rep 31: 2099-2106, 2014.

8. Zhang H, Cheng S, Zhang M, Ma X, Zhang L, Wang Y, Rong R, Ma J, Xia S, Du M, et al: Prostaglandin $\mathrm{E}_{2}$ promotes hepatocellular carcinoma cell invasion through upregulation of YB-1 protein expression. Int J Oncol 44: 769-780, 2014.

9. Xia S, Ma J, Bai X, Zhang H, Cheng S, Zhang M, Zhang L, Du M, Wang Y, Li H, et al: Prostaglandin $\mathrm{E}_{2}$ promotes the cell growth and invasive ability of hepatocellular carcinoma cells by upregulating c-Myc expression via EP4 receptor and the PKA signaling pathway. Oncol Rep 32: 1521-1530, 2014.

10. Bai X, Wang J, Guo Y, Pan J, Yang Q, Zhang M, Li H, Zhang L, Ma J, Shi F, et al: Prostaglandin E2 stimulates $\beta 1$-integrin expression in hepatocellular carcinoma through the EP1 receptor/PKC/ NF-кB pathway. Sci Rep 4: 6538, 2014.

11. Sun B, Rong R, Jiang H, Zhang H, Wang Y, Bai X, Zhang M, Ma J, Xia S, Shu W, et al: Prostaglandin $\mathrm{E}_{2}$ receptor EP1 phosphorylate CREB and mediates MMP2 expression in human cholangiocarcinoma cells. Mol Cell Biochem 378: 195-203, 2013.

12. Ma J, Chen M, Xia SK, Shu W, Guo Y, Wang YH, Xu Y, Bai XM, Zhang L, Zhang $\mathrm{H}$, et al: Prostaglandin $\mathrm{E}_{2}$ promotes liver cancer cell growth by the upregulation of FUSE-binding protein 1 expression. Int J Oncol 42: 1093-1104, 2013.

13. Cao J, Yang X, Li WT, Zhao CL and Lv SJ: Silencing of COX-2 by RNAi modulates epithelial-mesenchymal transition in breast cancer cells partially dependent on the PGE2 cascade. Asian Pac J Cancer Prev 15: 9967-9972, 2014.

14. Dufour M, Faes S, Dormond-Meuwly A, Demartines N and Dormond O: PGE2-induced colon cancer growth is mediated by mTORC1. Biochem Biophys Res Commun 451: 587-591, 2014.

15. Qiu X, Cheng JC, Chang HM and Leung PC: COX2 and PGE2 mediate EGF-induced E-cadherin-independent human ovarian cancer cell invasion. Endocr Relat Cancer 21: 533-543, 2014.

16. Wu T: Cyclooxygenase-2 and prostaglandin signaling in cholangiocarcinoma. Biochim Biophys Acta 1755: 135-150, 2005.

17. Kim SO, Dozier BL, Kerry JA and Duffy DM: EP3 receptor isoforms are differentially expressed in subpopulations of primate granulosa cells and couple to unique G-proteins. Reproduction 146: 625-635, 2013.

18. Lemieux E, Cagnol S, Beaudry K, Carrier J and Rivard N: Oncogenic KRAS signalling promotes the Wnt/ $\beta$-catenin pathway through LRP6 in colorectal cancer. Oncogene: Dec 15, 2014. http://dx.doi.org/10.1038/onc.2014.416.

19. Rath G, Jawanjal P, Salhan S, Nalliah M and Dhawan I: Clinical significance of inactivated glycogen synthase kinase 3beta in HPV-associated cervical cancer: Relationship with Wnt/betacatenin pathway activation. Am J Reprod Immunol 73: 460-478, 2015.

20. Vatansever HS, Gumus B, Aydogdu O, Sivrikoz ON, TürközUluer E, Kivanç M, Ateşçi YZ and Bugdayci H: The role of stem/ progenitor cells and $\mathrm{Wnt} / \beta$-catenin signaling pathway in the patients with prostate cancer. Minerva Urol Nefrol 66: 249-255, 2014.

21. Thompson MD and Monga SP: WNT/beta-catenin signaling in liver health and disease. Hepatology 45: 1298-1305, 2007.

22. Li P, Cao Y, Li Y, Zhou L, Liu X and Geng M: Expression of Wnt-5a and $\beta$-catenin in primary hepatocellular carcinoma. Int J Clin Exp Pathol 7: 3190-3195, 2014.

23. Ao R, Zhang DR, Du YQ and Wang Y: Expression and significance of Pin1, $\beta$-catenin and cyclin D1 in hepatocellular carcinoma. Mol Med Rep 10: 1893-1898, 2014. 
24. Gedaly R, Galuppo R, Daily MF, Shah M, Maynard E, Chen C, Zhang X, Esser KA, Cohen DA, Evers BM, et al: Targeting the $\mathrm{Wnt} / \beta$-catenin signaling pathway in liver cancer stem cells and hepatocellular carcinoma cell lines with FH535. PLoS One 9: e99272, 2014.

25. Tokumoto N, Ikeda S, Ishizaki Y, Kurihara T, Ozaki S, Iseki M, Shimizu Y, Itamoto T, Arihiro K, Okajima M, et al: Immunohistochemical and mutational analyses of Wnt signaling components and target genes in intrahepatic cholangiocarcinomas. Int J Oncol 27: 973-980, 2005.

26. Lim K, Han C, Xu L, Isse K, Demetris AJ and Wu T: Cyclooxygenase-2-derived prostaglandin $\mathrm{E}_{2}$ activates betacatenin in human cholangiocarcinoma cells: Evidence for inhibition of these signaling pathways by omega 3 polyunsaturated fatty acids. Cancer Res 68: 553-560, 2008.

27. Lee KB, Ye S, Park MH, Park BH, Lee JS and Kim SM: p63-Mediated activation of the $\beta$-catenin/c-Myc signaling pathway stimulates esophageal squamous carcinoma cell invasion and metastasis. Cancer Lett 353: 124-132, 2014.

28. Wang H, Zhang G, Zhang H, Zhang F, Zhou B, Ning F, Wang HS, Cai SH and Du J: Acquisition of epithelial-mesenchymal transition phenotype and cancer stem cell-like properties in cisplatin-resistant lung cancer cells through AKT/ $\beta$-catenin/ Snail signaling pathway. Eur J Pharmacol 723: 156-166, 2014.

29. Ripple MJ, Parker Struckhoff A, Trillo-Tinoco J, Li L, Margolin DA, McGoey R and Del Valle L: Activation of c-Myc and Cyclin D1 by JCV T-Antigen and $\beta$-catenin in colon cancer. PLoS One 9: e106257, 2014.

30. Manoukian AS and Woodgett JR: Role of glycogen synthase kinase- 3 in cancer: Regulation by Wnts and other signaling pathways. Adv Cancer Res 84: 203-229, 2002.

31. Castellone MD, Teramoto $\mathrm{H}$, Williams BO, Druey KM and Gutkind JS: Prostaglandin $\mathrm{E}_{2}$ promotes colon cancer cell growth through a Gs-axin-beta-catenin signaling axis. Science 310: 1504-1510, 2005.

32. Zheng WH, Kar S and Quirion R: Insulin-like growth factor-1induced phosphorylation of the forkhead family transcription factor FKHRL1 is mediated by Akt kinase in PC12 cells. J Biol Chem 275: 39152-39158, 2000.

33. Han C, Michalopoulos GK and Wu T: Prostaglandin $\mathrm{E}_{2}$ receptor EP1 transactivates EGFR/MET receptor tyrosine kinases and enhances invasiveness in human hepatocellular carcinoma cells. J Cell Physiol 207: 261-270, 2006.

34. Zhang L, Jiang L, Sun Q, Peng T, Lou K, Liu N and Leng J: Prostaglandin E2 enhances mitogen-activated protein kinase/ Erk pathway in human cholangiocarcinoma cells: Involvement of EP1 receptor, calcium and EGF receptors signaling. Mol Cell Biochem 305: 19-26, 2007.

35. Bos CL, Richel DJ, Ritsema T, Peppelenbosch MP and Versteeg HH: Prostanoids and prostanoid receptors in signal transduction. Int J Biochem Cell Biol 36: 1187-1205, 2004.

36. Orie NN and Clapp LH: Role of prostanoid IP and EP receptors in mediating vasorelaxant responses to PGI2 analogues in rat tail artery: Evidence for Gi/o modulation via EP3 receptors. Eur J Pharmacol 654: 258-265, 2011.

37. De Langhe SP and Reynolds SD: Wnt signaling in lung organogenesis. Organogenesis 4: 100-108, 2008.

38. Wodarz A and Nusse R: Mechanisms of Wnt signaling in development. Annu Rev Cell Dev Biol 14: 59-88, 1998.
39. Cui L, Jia X, Zhou Q, Zhai X, Zhou Y and Zhu H: Curcumin affects $\beta$-catenin pathway in hepatic stellate cell in vitro and in vivo. J Pharm Pharmacol 66: 1615-1622, 2014

40. Ge WS, Wang YJ, Wu JX, Fan JG, Chen YW and Zhu L: $\beta$-catenin is overexpressed in hepatic fibrosis and blockage of Wnt/ $\beta$-catenin signaling inhibits hepatic stellate cell activation. Mol Med Rep 9: 2145-2151, 2014

41. Pulkkinen K, Murugan S and Vainio S: Wnt signaling in kidney development and disease. Organogenesis 4: 55-59, 2008.

42. Nelson PJ, von Toerne $\mathrm{C}$ and Gröne HJ: Wnt-signaling pathways in progressive renal fibrosis. Expert Opin Ther Targets 15: 1073-1083, 2011

43. Wuebken A and Schmidt-Ott KM: WNT/ $\beta$-catenin signaling in polycystic kidney disease. Kidney Int 80: 135-138, 2011.

44. Terada Y, Tanaka H, Okado T, Shimamura H, Inoshita S, Kuwahara M and Sasaki S: Expression and function of the developmental gene Wnt-4 during experimental acute renal failure in rats. J Am Soc Nephrol 14: 1223-1233, 2003.

45. Hsu RJ, Ho JY, Cha TL, Yu DS, Wu CL, Huang WP, Chu P, Chen YH, Chen JT and Yu CP: WNT10A plays an oncogenic role in renal cell carcinoma by activating WNT/ $\beta$-catenin pathway. PLoS One 7: e47649, 2012.

46. Ueno K, Hirata H, Majid S, Tabatabai ZL, Hinoda $Y$ and Dahiya R: IGFBP-4 activates the Wnt/beta-catenin signaling pathway and induces M-CAM expression in human renal cell carcinoma. Int J Cancer 129: 2360-2369, 2011.

47. Lu D, Han C and Wu T: Microsomal prostaglandin E synthase-1 promotes hepatocarcinogenesis through activation of a novel EGR1/ $\beta$-catenin signaling axis. Oncogene 31: 842-857, 2012.

48. Llovet JM and Bruix J: Molecular targeted therapies in hepatocellular carcinoma. Hepatology 48: 1312-1327, 2008

49. Liu C, Li Y, Semenov M, Han C, Baeg GH, Tan Y, Zhang Z, Lin $\mathrm{X}$ and $\mathrm{He} \mathrm{X}$ : Control of beta-catenin phosphorylation/degradation by a dual-kinase mechanism. Cell 108: 837-847, 2002.

50. Hoppler S and Kavanagh CL: Wnt signalling: Variety at the core. J Cell Sci 120: 385-393, 2007.

51. Han $\mathrm{C}$ and $\mathrm{Wu} \mathrm{T}$ : Cyclooxygenase-2-derived prostaglandin $\mathrm{E}_{2}$ promotes human cholangiocarcinoma cell growth and invasion through $\mathrm{EP}_{1}$ receptor-mediated activation of the epidermal growth factor receptor and Akt. J Biol Chem 280: 24053-24063, 2005.

52. Glaysher S, Bolton LM, Johnson P, Atkey N, Dyson M, Torrance $\mathrm{C}$ and Cree IA: Targeting EGFR and PI3K pathways in ovarian cancer. Br J Cancer 109: 1786-1794, 2013.

53. Aasrum M, Odegård J, Sandnes D and Christoffersen T: The involvement of the docking protein Gabl in mitogenic signalling induced by EGF and HGF in rat hepatocytes. Biochim Biophys Acta 1833: 3286-3294, 2013.

54. Mouradian M, Kikawa KD, Johnson ED, Beck KL and Pardini RS: Key roles for GRB2-associated-binding protein 1, phosphatidylinositol-3-kinase, cyclooxygenase 2, prostaglandin E2 and transforming growth factor alpha in linoleic acidinduced upregulation of lung and breast cancer cell growth. Prostaglandins Leukot Essent Fatty Acids 90: 105-115, 2014.

55. Cardoso AP, Pinto ML, Pinto AT, Oliveira MI, Pinto MT, Gonçalves R, Relvas JB, Figueiredo C, Seruca R, Mantovani A, et al: Macrophages stimulate gastric and colorectal cancer invasion through EGFR Y(1086), c-Src, Erk1/2 and Akt phosphorylation and smallGTPase activity. Oncogene 33: 2123-2133, 2014. 